\title{
Chemical Communication between Phytopathogens, Their Host Plants and Vector Insects and Eavesdropping by Natural Enemies
}

\author{
Jürgen Gross ${ }^{1,2 *}$ \\ ${ }^{1}$ Chemical Ecology/Phytopathology Lab, Institute for Plant Protection in Fruit Crops and Viticulture, Federal Research Centre \\ for Cultivated Plants, Julius Kühn-Institut, Dossenheim, Germany, ${ }^{2}$ Institute of Evolutionary Ecology and Conservation \\ Genomics, University of Ulm, Ulm, Germany
}

Keywords: Candidatus Phytoplasma, Candidatus Liberibacter, plant virus, voc, multitrophic interactions, behavior modification

\section{A commentary on}

Plant pathogen-induced volatiles attract parasitoids to increase parasitism of an insect vector by Martini, X., Pelz-Stelinski, K. S., and Stelinski, L. L. (2014). Front. Ecol. Evol. 2:8. doi: $10.3389 /$ fevo.2014.00008

\section{INTRODUCTION}

OPEN ACCESS

Edited by:

Stefano Colazza,

University of Palermo, Italy

Reviewed by:

Paul J. Ode,

Colorado State University, USA

Thomas Seth Davis,

Colorado State University, USA

*Correspondence:

Jürgen Gross

juergen.gross@julius-kuehn.de

Received: 12 June 2016 Accepted: 12 August 2016

Published: 25 August 2016

Citation:

Gross J (2016) Chemical

Communication between

Phytopathogens, Their Host Plants and Vector Insects and Eavesdropping by Natural Enemies.

Front. Ecol. Evol. 4:104.

doi: 10.3389/fevo.2016.00104
Evolutionary adaptations in plant, microorganism and arthropod interactions are primarily studied in systems involving only two of these groups: plants and microbes, plants and arthropods, or arthropods and microbes (Biere and Tack, 2013). Beside this, it was stated recently that there is emerging evidence that three-way interactions between plants, arthropods and microorganisms can play a major role in shaping ecological communities (Tack and Dicke, 2013). Moreover, the study of three-way interactions should not only include the mediation of plant-arthropod interactions by arthropod associated microorganisms or mutualistic plant associated microbes as proposed by Biere and Tack (2013), but should also include plant pathogens and arthropod antagonists (predators and parasitoids). Unfortunately, to date little is known about the influence of plant pathogens on the third trophic level. Thus, in this commentary the importance of a multitrophic research approach covering more than three-way interactions, as it was studied recently by Martini et al. (2014), is highlighted.

\section{PLANT-PHYTOPATHOGEN-VECTOR INTERACTIONS}

Most phloem-dwelling plant pathogens like viruses and bacteria (e.g., Candidatus Phytoplasma, $\mathrm{Ca}$. Liberibacter) are dependent on insect vectors for plant-to-plant transmission (Orlovskis et al., 2015). Although a number of taxa are vectors of different plant viruses (Ng and Falk, 2006), species belonging to phloem-feeding order Hemiptera are the most important vectors of plant viruses, phytoplasmas ( $\mathrm{Ca}$. Phytoplasma) and proteobacteria (Ca. Liberibacter) (Weintraub and Beanland, 2006; Hogenhout et al., 2008). Besides visual (Farnier et al., 2014, 2015) and tactile signals, these vector insects use information provided by plant odors (kairomones) for the identification of appropriate hosts for feeding and oviposition (Orlovskis et al., 2015). These volatile organic 
compounds (VOCs) may be produced constitutively (Soroker et al., 2004) or can be induced by plant pathogens (Mayer et al., 2008a,b; Rid et al., 2016).

Many $\mathrm{Ca}$. Phytoplasma and $\mathrm{Ca}$. Liberibacter vectors use chemical cues for the identification of their host plants (Mayer et al., 2008a,b; Mann et al., 2012). It has been shown in recent years that some phytopathogens manipulate the behavior of their vectors by altering the attractiveness of the vector's host plants by increasing the amount or changing the composition of VOCs emitted by infected plants. This has been shown for pathogenic bacteria (Mayer et al., 2008a,b; Davis et al., 2012; Mann et al., 2012; Shapiro et al., 2012; Mas et al., 2014) and viruses (Eigenbrode et al., 2002; Mauck et al., 2010). Recently it was shown that the apple proliferation phytoplasma $\mathrm{Ca}$. Phytoplasma mali influenced the pattern of plant volatiles emitted by its host plant depending on the pathogen virulence (Rid et al., 2016). The analysis of the complex, chemically mediated three-way interactions between $\mathrm{Ca}$. P. mali, its vector Cacopsylla picta (Hemiptera: Psyllidae) and their host plants (both the reproduction and overwintering hosts), showed that this phytoplasma changed the odor of the reproduction host plant to attract the highly adapted vector to infected apple plants (Mayer et al., 2008a,b). Phytoplasma infection induces apple trees to produce more $\beta$-caryophyllene which preferentially attracts newly eclosed C. picta just before they emigrate to their overwintering host. By feeding on infected plants, the probability of acquisition of the phytoplasma increases. After overwintering on conifers, the psyllids return to apple plants but now prefer to lay their eggs on uninfected plants due to deleterious effects of the phytopathogen on the developing offspring, thereby increasing the opportunity to transmit the phytoplasma (Mayer et al., 2011). Similarly, the cucumber mosaic virus reduced the quality but increased the attractiveness of its host plant Cucurbita pepo for two aphid vectors, namely Myzus persicae and Aphis gossypii, due to virus-induced increased emissions of a VOC blend similar to that emitted by healthy plants (Mauck et al., 2010). Because the vectors performed poorly on infected plants, they rapidly emigrated from them, a pattern highly conducive to the nonpersistent transmission mechanism employed by this virus (Mauck et al., 2010). Ingwell et al. (2012) showed that the aphid Rhopalosiphum padi, after acquiring Barley yellow dwarf virus (BYDV) during in vitro feeding, preferred uninfected wheat plants, while uninfective aphids also fed in vitro preferred BYDV-infected plants. This behavioral change should promote pathogen spread since uninfective vector preference for infected plants will promote acquisition, while infective vector preference for uninfected hosts will promote transmission. In conclusion, as shown for both bacterial and virus phytopathogens, behavioral changes of the vectors promote both pathogen acquisition and transmission. Both plant pathogenic bacteria and viruses can either increase, decrease, or have a neutral effect on their vector's fitness (lifespan, fecundity, and survival) (Madden and Nault, 1983; Ebbert and Nault, 1994, 2001; Beanland et al., 2000; PelzStelinski and Killiny, 2016). Beneficial effects of phytopathogens on vector fitness may indicate that the pathogen has an evolutionarily older relationship with its insect host while detrimental effects may indicate an evolutionarily younger relationship.

\section{EAVESDROPPING OF PLANT-PHYTOPATHOGEN-VECTOR INTERACTIONS BY NATURAL ENEMIES}

Many plants attacked by herbivores emit leaf VOCs that attract their natural enemies, such as parasitoids and predators (Dicke et al., 1990; Turlings and Wäckers, 2004). But to date, little is known about the effect of phytopathogens on organisms of the third trophic level. Indeed, this problem is especially interesting in cases where phytopathogens manipulate their host plants by eliciting increased VOC emission (either qualitatively or quantitatively) to increase their attractiveness to herbivorous vectors (Mayer et al., 2008a,b; Mauck et al., 2010; Mann et al., 2012). Thus, besides chemical signals emitted by herbivore infested host plants ("cry for help": synomones) and vector odors (host or prey kairomones), eavesdropping on plant volatiles induced by phytopathogen infection to attract its vector (allomones) may additionally increase the host seeking effectiveness of the natural enemy (Figure 1). As shown by Martini et al. (2014), a parasitoid may take advantage of an altered extended phenotype to increase its foraging performance. They also investigated the bacterial phytopathogen Las, which elicits the release of methyl salicylate by its host plant (Citrus spp.) to attract its vector, the psyllid Diaphorina citri (Mann et al., 2012). Martini et al. (2014) found that the specialist parasitoid of $D$. citri, the ectoparasitoid wasp Tamarixia radiata (Hymenoptera: Eulophidae), was attracted more toward Lasinfected and uninfected plants baited with methyl salicylate than to uninfected plants. Parasitization of D. citri nymphs on Las-infected plants was higher than on uninfected controls. This remarkable study is the first report of a parasitoid "eavesdropping" on VOCs induced by a phytopathogen which has apparently evolved to increase the effectiveness of the host seeking behavior of its herbivorous vector. Recently, (Mauck et al., 2015) observed higher rates of aphid parasitism by the parasitoid Aphidius colemani (Hymenoptera: Braconidae) on virus infected cucumber compared to healthy plants. This was due to a decreased fitness of aphids feeding on infected plants with reduced nutritional quality.

Insect vectors and their natural enemies might not be the only trophic levels influenced by phytopathogens. Sun et al. (2016) recently demonstrated that infection of rice by the pathogenic bacterium Xanthomonas oryzae pv. oryzae significantly influenced the interactions of rice plants with a nonvectoring herbivore, the brown rice planthopper Nilaparvata lugens (Hemiptera: Delphacidae), and its major predator, Cyrtorhinus lividipennis (Hemiptera: Miridae). The numbers of this phloem feeder on infected rice plants at $15 \mathrm{~d}$ post-inoculation were two to four times higher than on healthy rice plants. After the rice plants had been fed on by planthoppers, adult C. lividipennis showed a higher preference for infected plants $10 \mathrm{~d}$ post-inoculation, which was attributed to higher emission rates of herbivore induced volatiles from infected plants. Thus, 


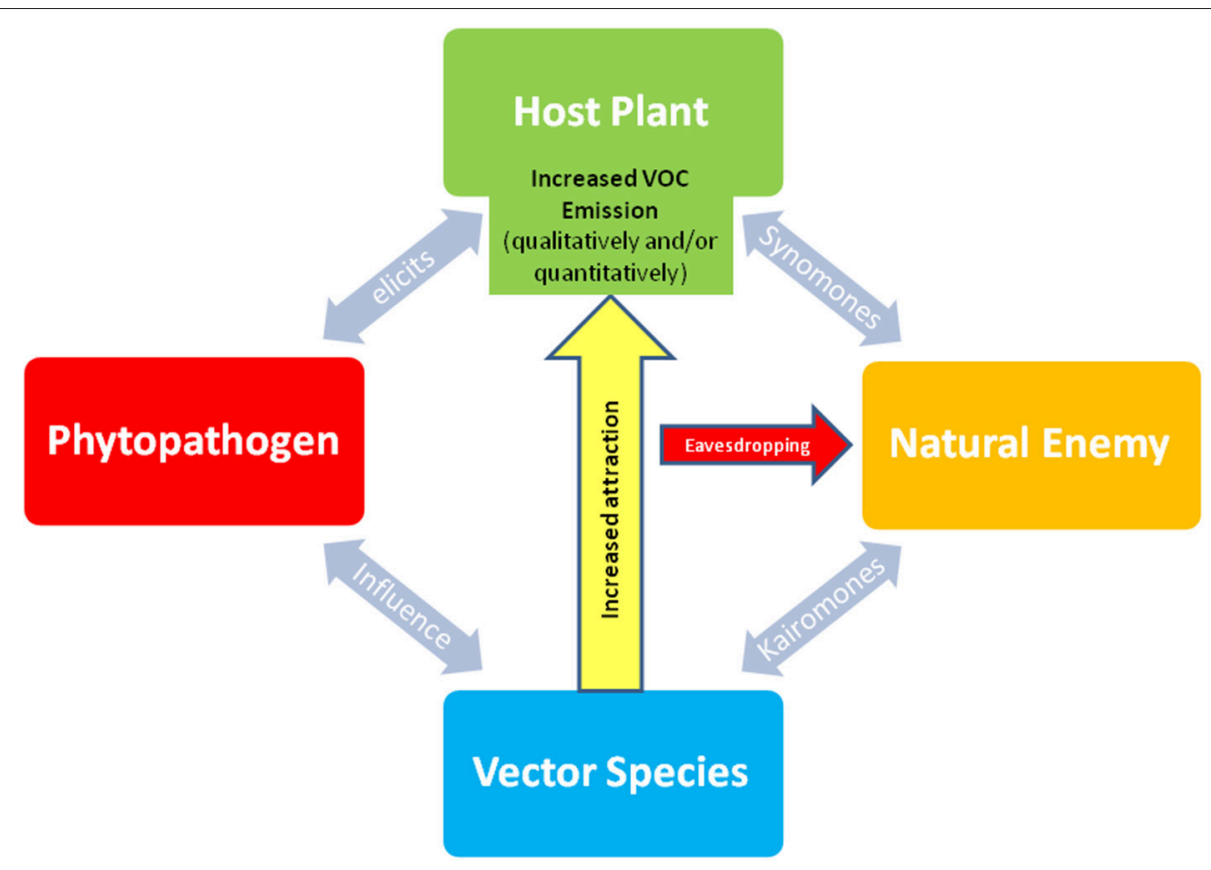

FIGURE 1 | Chemically mediated multitrophic interactions between plants, phytopathogens, and vector organisms eavesdropped by insect natural enemies (parasitoid, predator). The influence of a phytopathogen (e.g., virus, Ca. Phytoplasma, Ca. Liberibacter or fungus) on plant physiology elicits the emission of new VOC or increase the production of higher amounts of VOC by host plant what may influence vector behavior by increasing its attraction. Thus, besides chemical signals directly emitted by insect infested host plants (synomones) and vector odors (kairomones), eavesdropping on plant volatiles induced by phytopathogen infection to attract its vector (allomones) may additionally increase the host seeking effectiveness of the natural enemy.

quantitatively increased VOC emission by the plant as a result of the pathogen at a specific time period was used by the predator to locate its prey.

Of particular interest is time dependent eavesdropping of plant-phytopathogen-vector interactions by natural enemies. Since the vector is attracted to infected plants for feeding at specific stages in its life cycle, eavesdropping parasitoids could associate perception of the induced odor with host availability. Interestingly, the parasitoid was also attracted to infected plants without vectors (Martini et al., 2014). However, in another plantphytopathogen-vector system, infected plants were nutritionally sub-optimal to the psyllid $D$. citri when compared to uninfected plants (Mann et al., 2012). The same was found earlier for the psyllid C. picta which exhibited increased mortality and reduced body size after developing on phytoplasma-infected apple plants, the result of which was greater attraction to healthy plants by ovipositing females (Mayer et al., 2011). In yet another example, the psyllid Bactericera cockerelli also preferred to oviposit on uninfected potato plants compared to potatoes infected with Candidatus Liberibacter solanacearum (Davis et al., 2012). As a consequence, during periods of oviposition, the number of vectors should be reduced on infected plants. Thus, pathogeninduced volatiles not only deceive the vector but can do so as well with their associated parasitoids, resulting in a better spread of the pathogen (Martini et al., 2014).

While multitrophic interactions involve more than three trophic levels in a food web (e.g., plants, plant pathogens, vectoring herbivorous insects, and their antagonists), the main focus of research on these complex interactions is to identify the different driving forces regulating population dynamics of the involved species. Plant morphology, as well as primary and secondary plant compounds (including VOC), are major traits determining interactions between green plants and higher trophic levels (Schoonhoven et al., 1998; de Boer et al., 2008). Most plant viruses do not appear to cause diseases in wild plants but virus infected plants maybe benefited by virus infection (Roossinck, 2015). The interactions between viruses and plants vary from mutualism to antagonism, or pathogenesis (Roossinck, 2015), and may be influenced by changing environments (Davis et al., 2015). The ability of species from higher trophic levels to respond differentially to variations in these factors may drive natural selection (Futuyma, 2000). The potential for natural enemies of vector insects to act as selective forces in the evolution on plant-phytopathogen interactions is not well studied as yet. As shown in many examples of plants infected with pathogenic bacteria and viruses, the manipulation of plant odors by phytopathogens can increase the plants' attractiveness for vectors. As a consequence, the attraction of natural enemies eavesdropping the same signal may similarly reduce the numbers of vectors transmitting the phytopathogen, appearing a new mechanism of indirect defense of infected plants against manipulating phytopathogens and their vectors, respectively. Thus, the eavesdropping behavior of the natural enemy could be a mutualistic plant relationship but counteract 
the pathogen-vector interaction. For a deeper understanding of the evolutionary context of these interactions we need to know more examples than the one recently reported by Martini et al. (2014).

In conclusion, the research presented by (Martini et al., 2014) contributes significantly to our understanding of chemically mediated multitrophic interactions involving more than three trophic levels in a food web. By investigating natural enemies

\section{REFERENCES}

Beanland, L., Hoy, C. W., Miller, S. A., and Nault, L. R. (2000). Influence of aster yellows phytoplasma on the fitness of aster leafhopper (Homoptera: Cicadellidae). Ann. Entomol. Soc. Am. 93, 271-276. doi: 10.1603/00138746(2000)093[0271:IOAYPO]2.0.CO;2

Biere, A., and Tack, A. J. M. (2013). Evolutionary adaptation in three-way interactions between plants, microbes and arthropods. Funct. Ecol. 27, 646-660. doi: 10.1111/1365-2435.12096

Davis, T. S., Bosque-Pérez, N. A., Foote, N. E., Magney, T., and Eigenbrode, S. D. (2015). Environmentally dependent host-pathogen and vector-pathogen interactions in the Barley yellow dwarf virus pathosystem. J. Appl. Ecol. 52, 1392-1401. doi: 10.1111/1365-2664.12484

Davis, T. S., Horton, D. R., Munyaneza, J. E., and Landolt, P. J. (2012). Experimental infection of plants with an herbivore-associated bacterial endosymbiont influences herbivore host selection behavior. PLoS ONE 7:e49330. doi: 10.1371/journal.pone.0049330

de Boer, J. G., Hordijk, C. A., Posthumus, M. A., and Dicke, M. (2008). Prey and non-prey arthropods sharing a host plant: effects on induced volatile emission and predator attraction. J. Chem. Ecol. 34, 281-290. doi: 10.1007/s10886-0079405-z

Dicke, M., Sabelis, M. W., Takabayashi, J., Bruin, J., and Posthumus, M. A. (1990). Plant strategies of manipulating predator-prey interactions through allelochemicals: prospects for application in pest control. J. Chem. Ecol. 16, 3091-3118. doi: 10.1007/BF00979614

Ebbert, M. A., and Nault, L. R. (1994). Improved overwintering ability in Dalbulus maidis (Homoptera: Cicadellidae) vectors infected with Spiroplasma kunkelii (Mycoplasmatales: Spiroplasmataceae). Environ. Entomol. 23, 634-644. doi: 10.1093/ee/23.3.634

Ebbert, M. A., and Nault, L. R. (2001). Survival in Dalbulus leafhopper vectors improves after exposure to maize stunting pathogens. Entomol. Exp. Appl. 100, 311-324. doi: 10.1046/j.1570-7458.2001.00878.x

Eigenbrode, S. D., Ding, H. J., Shiel, P., and Berger, P. H. (2002). Volatiles from potato plants infected with potato leafroll virus attract and arrest the virus vector, Myzus persicae (Homoptera: Aphididae). Proc. R. Soc. B. 269, 455-460. doi: 10.1098/rspb.2001.1909

Farnier, K., Dyer, A. G., and Steinbauer, M. J. (2014). Related but not alike: not all Hemiptera are attracted to yellow. Front. Ecol. Evol. 2:67. doi: 10.3389/fevo.2014.00067

Farnier, K., Dyer, A. G., Taylor, G. S., Peters, R. A., and Steinbauer, M. J. (2015). Visual acuity trade-offs and microhabitat-driven adaptation of searching behaviour in psyllids (Hemiptera: Psylloidea: Aphalaridae). J. Exp. Biol. 218, 1564-1571. doi: 10.1242/jeb.120808

Futuyma, D. (2000). Some current approaches to the evolution of plant-herbivore interactions. Plant Spec. Biol. 15, 1-9. doi: 10.1046/j.1442-1984.2000.00029.x

Hogenhout, S. A., Ammar, E. D., Whitfield, A. E., and Redinbaugh, M. G. (2008). Insect vector interactions with persistently transmitted viruses. Annu. Rev. Phytopathol. 46, 327-359 doi: 10.1146/annurev.phyto.022508. 092135

Ingwell, L. L., Eigenbrode, S. D., and Bosque-Pérez, N. A. (2012). Plant viruses alter insect behavior to enhance their spread. Sci. Rep. 2:578. doi: 10.1038/srep 00578

Madden, L. V., and Nault, L. R. (1983). Differential pathogenicity of corn stunting mollicutes to leafhopper vectors in Dalbulus and Baldulus species. Phytopathology 73, 1608-1614. doi: 10.1094/Phyto-73-1608 eavesdropping plant-phytopathogen-vector interactions they have opened an interesting new research avenue in chemical ecology.

\section{AUTHOR CONTRIBUTIONS}

The author confirms being the sole contributor of this work and approved it for publication.

Mann, R. S., Ali, J. G., Hermann, S. L., Tiwari, S., Pelz-Stelinski, K. S., Alborn, H. T., et al. (2012). Induced release of a plant-defense volatile "deceptively" attracts insect vectors to plants infected with a bacterial pathogen. PLoS Pathog. 8:e1002610. doi: 10.1371/journal.ppat.1002610

Martini, X., Pelz-Stelinski, K. S., and Stelinski, L. L. (2014). Plant pathogen-induced volatiles attract parasitoids to increase parasitism of an insect vector. Front. Ecol. Evol. 2:8. doi: 10.3389/fevo.2014.00008

Mas, F., Vereijssen, J., and Suckling, D. M. (2014). Influence of the pathogen Candidatus Liberibacter solanacearum on tomato host plant volatiles and psyllid vector settlement. J. Chem. Ecol. 40, 1197-1202. doi: 10.1007/s10886014-0518-x

Mauck, K. E., De Moraes, C. M., and Mescher, M. C. (2010). Deceptive chemical signals induced by a plant virus attract insect vectors to inferior hosts. Proc. Natl. Acad. Sci. U.S.A. 107, 3600-3605. doi: 10.1073/pnas.0907191107

Mauck, K. E., De Moraes, C. M., and Mescher, M. C. (2015). Infection of host plants by Cucumber mosaic virus increases the susceptibility of Myzus persicae aphids to the parasitoid Aphidius colemani. Sci. Rep. 5:10963. doi: 10.1038/srep10963

Mayer, C. J., Vilcinskas, A., and Gross, J. (2008a). Pathogen-induced release of plant allomone manipulates vector insect behavior. J. Chem. Ecol. 34, 1518-1522. doi: 10.1007/s10886-008-9564-6

Mayer, C. J., Vilcinskas, A., and Gross, J. (2008b). Phytopathogen lures its insect vector by altering host plant odor. J. Chem. Ecol. 34, 1045-1049. doi: 10.1007/s10886-008-9516-1

Mayer, C. J., Vilcinskas, A., and Gross, J. (2011). Chemically mediated multitrophic interactions in a plant-insect vector-phytoplasma system compared with a partially nonvector species. Agric. Forest Entomol. 13, 25-35. doi: 10.1111/j.1461-9563.2010.00495.x

Ng, J. C. K., and Falk, B. W. (2006). Virus-vector interactions mediating nonpersistent and semipersistent transmission of plant viruses. Ann. Rev. Phytopathol. 44, 183 -212. doi: 10.1146/annurev.phyto.44.070505. 143325

Orlovskis, Z., Canale, M. C., Thole, V., Pecher, P., Lopes, J. R., and Hogenhout, S. A. (2015). Insect-borne plant pathogenic bacteria: getting a ride goes beyond physical contact. Curr. Opin. Insect Sci. 9, 16-23. doi: 10.1016/j.cois.2015. 04.007

Pelz-Stelinski, K. S., and Killiny, N. (2016). Better together: association with 'Candidatus Liberibacter Asiaticus' increases the reproductive fitness of its insect vector, Diaphorina citri (Hemiptera: Liviidae). Ann. Entomol. Soc. Am. doi: 10.1093/aesa/saw007. [Epub ahead of print].

Rid, M., Mesca, C., Ayasse, M., and Gross, J. (2016). Apple proliferation phytoplasma influences the pattern of plant volatiles emitted depending on pathogen virulence. Front. Ecol. Evol. 3:152. doi: 10.3389/fevo.2015.00152

Roossinck, M. J. (2015). Plants, viruses and the environment: ecology and mutualism. Virology 479-480, 271-277. doi: 10.1016/j.virol.2015. 03.041

Schoonhoven, L. M., Jermy, T., and Loon, J. (eds.). (1998). Insect-Plant Biology: from Physiology to Evolution, 1st Edn. London: Chapman and Hall Ltd.

Shapiro, L., De Moraes, C. M., Stephenson, A. G., and Mescher, M. C. (2012). Pathogen effects on vegetative and floral odours mediate vector attraction and host exposure in a complex pathosystem. Ecol. Lett. 15, 1430-1438. doi: 10.1111/ele.12001

Soroker, V., Talebaev, S., Harari, A. R., and Wesley, S. D. (2004). The role of chemical cues in host and mate location in the pear psylla Cacopsylla bidens (Homoptera: Psyllidae). J. Insect Behav. 17, 613-626. doi: 10.1023/B:JOIR.0000042544.35561.1c 
Sun, Z., Liu, Z., Zhou, W., Jin, H., Liu, H., Zhou, A., et al. (2016). Temporal interactions of plant - insect - predator after infection of bacterial pathogen on rice plants. Sci. Rep. 6:26043. doi: 10.1038/srep26043

Tack, A. J. M., and Dicke, M. (2013). Plant pathogens structure arthropod communities across multiple spatial and temporal scales. Funct. Ecol. 27, 633-645. doi: 10.1111/1365-2435.12087

Turlings, T. C., and Wäckers, F. (2004). "Recruitment of predators and parasitoids by herbivore-injuried plants," in Advances in Insect Chemical Ecology, eds R. T. Carde and G. M. Millar (Cambridge: Cambridge University Press), 21-75.

Weintraub, P. G., and Beanland, L. (2006). Insect vectors of phytoplasmas. Annu. Rev. Entomol. 51, 91-111. doi: 10.1146/annurev.ento.51.110104.151039
Conflict of Interest Statement: The author declares that the research was conducted in the absence of any commercial or financial relationships that could be construed as a potential conflict of interest.

Copyright (c) 2016 Gross. This is an open-access article distributed under the terms of the Creative Commons Attribution License (CC BY). The use, distribution or reproduction in other forums is permitted, provided the original author(s) or licensor are credited and that the original publication in this journal is cited, in accordance with accepted academic practice. No use, distribution or reproduction is permitted which does not comply with these terms. 